\title{
Nutrition during pregnancy and early development (NuPED) in urban South Africa: a study protocol for a prospective cohort
}

\author{
Elizabeth A. Symington ${ }^{1,2^{*}}$ D, Jeannine Baumgartner ${ }^{1}$, Linda Malan ${ }^{1}$, Lizelle Zandberg ${ }^{1}$, Cristian Ricci ${ }^{1}$ \\ and Cornelius M. Smuts ${ }^{1}$
}

\begin{abstract}
Background: Adequate nutrition during pregnancy is important to ensure optimal birth outcomes, maternal health and offspring development. However, little is known about the dietary intake and nutritional status of pregnant women residing in urban South Africa. Therefore, the Nutrition during Pregnancy and Early Development (NuPED) cohort study was initiated to assess early nutrition-related exposures predictive of early childhood development in urban South Africa.

Methods: The aims of this prospective cohort study are: 1) to assess dietary intake and nutritional status of urban pregnant women in Johannesburg, South Africa, and 2) to determine associations with birth outcomes, measures of maternal health, as well as measures of offspring health and development. Pregnant women ( $<18$ weeks' gestation) $(n=250)$ are being recruited from primary healthcare clinics in Johannesburg and are followed-up at a provincial hospital. Participants' dietary intake and nutrient status (focus on micronutrients and fatty acids) are assessed at $<18,22$ and 36 weeks' gestation. Additional assessments during pregnancy include anthropometric and blood pressure measurements, obstetric ultrasound screens, and assessments of food security, maternal fatigue, prenatal depression, allergy, immune function, morbidity and gestational diabetes. At birth, maternal and neonatal health is assessed and an umbilical cord blood sample collected. Maternal and offspring health is followed-up at 6 weeks, as well as at $6, \approx 7.5$ and 12 months after birth. Follow-up assessments of mothers include anthropometric measures, diet history, nutrient status, blood pressure, breast milk composition, and measures of postnatal depression and fatigue. Follow-up assessments of the offspring include feeding practices, nutrient status, measures of growth, psychomotor, socio-emotional and immune development, morbidity, allergy, as well as analysis of the gut microbiome and the epigenome.
\end{abstract}

Discussion: Ensuring adequate nutrition during pregnancy is one of the key actions endorsed by the South African Government to promote optimal early childhood development in an effort to eradicate poverty. The results from this study may serve as a basis for the development of context-specific nutritional interventions which can improve birth outcomes and long-term quality of life of the mother and her offspring.

Keywords: Maternal health, Maternal diet, Nutrition, Pregnancy, Birth outcomes, Early development, DOHaD

\footnotetext{
* Correspondence: syminea@unisa.ac.za

${ }^{1}$ Centre of Excellence for Nutrition, North-West University, Potchefstroom,

South Africa

${ }^{2}$ Department of Life and Consumer Sciences, University of South Africa,

Johannesburg, South Africa
}

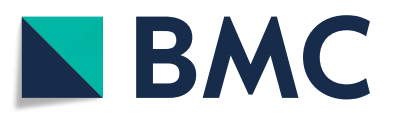

(c) The Author(s). 2018 Open Access This article is distributed under the terms of the Creative Commons Attribution 4.0 International License (http://creativecommons.org/licenses/by/4.0/), which permits unrestricted use, distribution, and reproduction in any medium, provided you give appropriate credit to the original author(s) and the source, provide a link to the Creative Commons license, and indicate if changes were made. The Creative Commons Public Domain Dedication waiver (http://creativecommons.org/publicdomain/zero/1.0/) applies to the data made available in this article, unless otherwise stated. 


\section{Background}

Recent estimates indicate that 250 million children in low- and middle income countries are at risk of not reaching their developmental potential [1]. This is worrisome as suboptimal childhood development is associated with poorer adult health, well-being and productivity leading to an intergenerational cycle of poverty. As the trajectories of physical and mental health later in life are determined fundamentally during the first 1000 days of life, both the World Health Assembly Nutrition Targets and the Sustainable Developmental Goals call for action to, among others, improve maternal, infant and young child nutrition in an effort to ensure sustainable social and economic progress.

Maternal health and nutrition gained heightened attention three decades ago with the publication of the developmental origins of health and disease $(\mathrm{DOHaD})$ hypothesis. Barker and Osmond [2] proposed that the cardiovascular disease they observed in an adult population from England and Wales was at least partly associated with poor early nutrition, and specifically undernutrition in utero [3]. Undernourishment in utero can stress the foetus in ways that permanently affect physiological growth and development, and can be described as a reprogramming of the foetus's developing phenotype [4]. Apart from the long-term health consequences, severe growth-restricted foetuses are at increased risk of stillbirth, and the live births have an increased risk of neonatal death, morbidity and permanent deficits in growth and neurocognitive development $[5,6]$.

Several maternal nutritional factors have been investigated in relation to adverse pregnancy outcomes, as well as offspring health and development [7-9]. The nutrients most studied during pregnancy include B-vitamins (particularly folic acid), vitamin D, iron, long-chain polyunsaturated fatty acids (particularly n-3 fatty acids) and iodine $[8,10]$. However, adequate maternal intakes of zinc and vitamin A may also be important for optimal pregnancy outcomes, as well as for maternal and offspring health [11-13]. Furthermore, better overall diet quality has been associated with a lower risk for maternal perinatal depression and gestational weight gain, which in turn are risk factors for suboptimal offspring development [14-16].

The health of the adult South African population is a concern. South Africa has large economic disparities and $20 \%$ of the population are living in extreme poverty, indicating they cannot afford the minimum required food intake [17]. During a national survey in 2012, approximately $40 \%$ of the population were reported to have a monotonous diet based mainly on starches [18]. The country is undergoing a rapid nutrition transition characterised by changes in dietary patterns and nutrient intake alongside urbanisation $[19,20]$, which has resulted in a growing double-burden of under- and over-nutrition [20, 21].
Hence, not surprisingly, $31 \%$ and $13 \%$ of South African women of reproductive age are anaemic [22] and vitamin A deficient [18], respectively, while $68 \%$ of women are overweight or obese, and $46 \%$ hypertensive [22]. The effects are also seen in children, with $27 \%$ of under-fives being stunted [22]. Both stunting and poverty are known risk factors for poor child development [23]. Maternal short stature is, in turn, a risk factor for birth complications [24] - illustrating the intergenerational effect of poor nutrition.

Ensuring adequate nutrition during pregnancy is one of the key actions endorsed by the South African Government to promote optimal early childhood development in an effort to eradicate poverty [25]. The Guidelines for maternity care in South Africa [26] therefore recommend routine nutritional assessment - such as measuring mid-upper arm circumference and haemoglobin levels - and daily supplementation of $200 \mathrm{mg}$ ferrous sulphate, $1000 \mathrm{mg}$ calcium and $5 \mathrm{mg}$ folic acid. However, studies show that the majority of South African women only seek or get access to public antenatal care in their second trimester of pregnancy [27-30], which might be too late for the routine supplementation programme or other interventions to be effective.

Very little is known about the diet and nutritional status of pregnant women in South Africa, specifically residing in urban areas. Furthermore, understanding the associations of maternal diet and nutritional status during pregnancy with birth outcomes, as well as offspring health and development in the South African population will form the basis for the development of context-specific nutrition interventions that may improve birth outcomes and long-term quality of life of the mother and her offspring. Consequently, the Nutrition during Pregnancy and Early Development (NuPED) cohort study was initiated to investigate nutritional status during pregnancy and assess early nutrition-related exposures predictive of early childhood development in urban South Africa.

\section{Aims of the study}

The aims of the NuPED study are 1) to assess dietary intake and nutritional status of urban pregnant women in Johannesburg, South Africa, and 2) to determine associations with birth outcomes, measures of maternal health, as well as measures of offspring health and development. A simplistic conceptual framework showing the modifiable and non-modifiable exposure variables, as well as the outcome variables that will be determined to achieve the aims, is shown in Fig. 1.

\section{Methods/design \\ Study design}

This prospective cohort study follows 250 women throughout pregnancy to birth, and their infants up to 


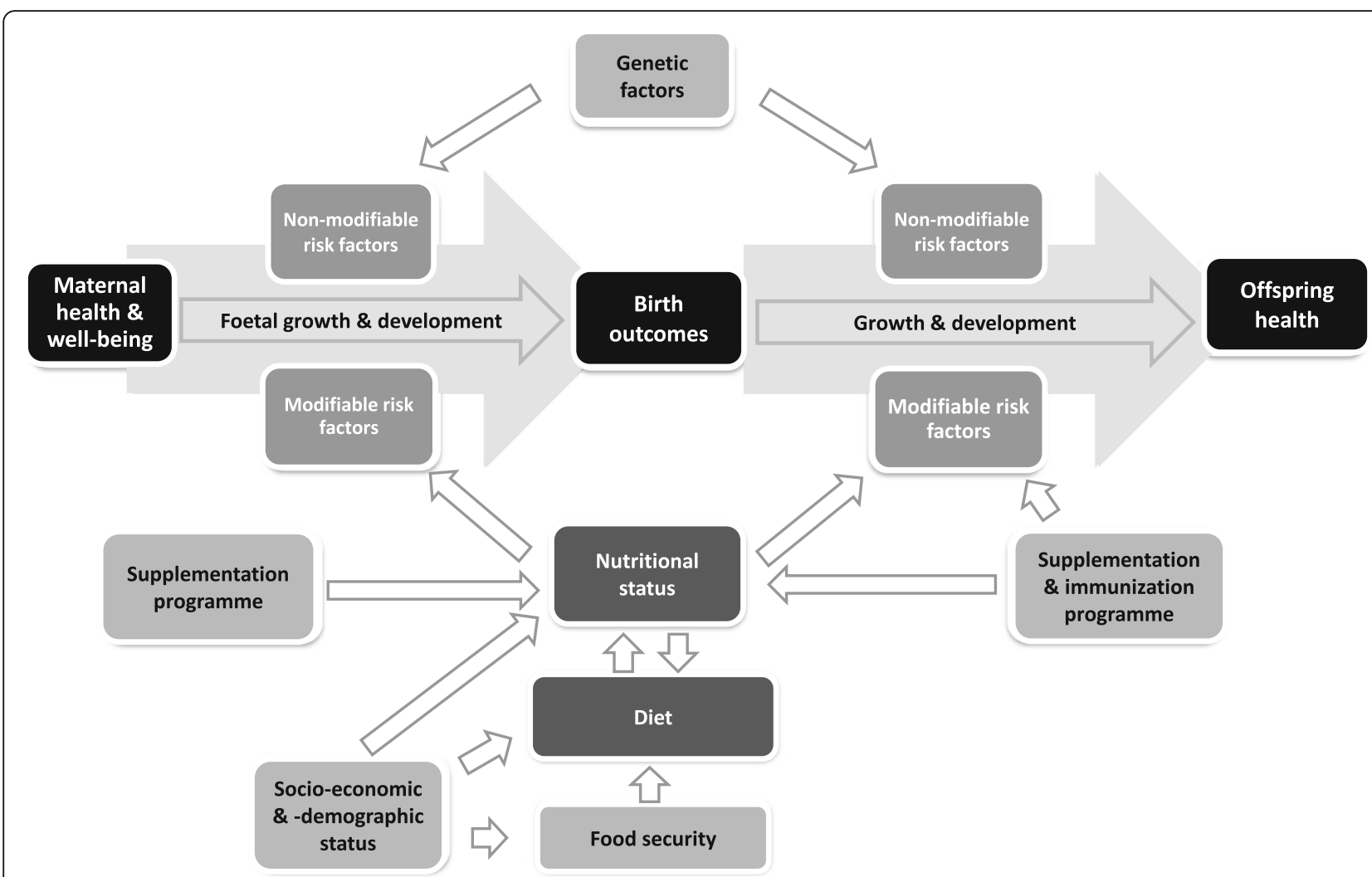

Fig. 1 Simplistic conceptual framework of exposure and outcome variables in the NuPED study. The study investigates the indicated variables from early pregnancy to infants up to 12 months. The variables fall mainly in the modifiable risk factors category with the core interest being nutritional status. The outcome variables include birth outcomes such as birth weight and gestational age as well as postnatal growth and psychomotor development

12 months of age. Briefly, data are collected early pregnancy, mid-pregnancy, late pregnancy and at birth. Postnatal assessments focus mainly on offspring health and development at 6 weeks, 6 months, 7.5 months $(6$ months + 6 weeks) and 12 months' postnatal age.

Recruitment of participants started on 7 March 2016 and completion of data collection is expected in June 2019.

\section{Setting}

The study is situated in Johannesburg, the largest city in South Africa. Recruitment of study participants takes place in two of the seven municipal regions of the city from which four primary health care clinics were identified. These clinics fall in the catchment area of Rahima Moosa Mother and Child Hospital (RMMCH). RMMCH is a provincial hospital focusing on maternal and paediatric healthcare, delivering more than 10,000 babies annually. Pregnancy data are collected at the antenatal care (ANC) clinic of $\mathrm{RMMCH}$ in addition to routine care. Birth data are collected in the relevant wards at RMMCH. Postnatal data are collected at the Empilweni Services and Research Unit (ESRU) at RMMCH. The execution of the study is coordinated by the Centre of Excellence for Nutrition of the North-West University.

\section{Study population}

The study population is urban pregnant women attending $\mathrm{ANC}$ at either one of four selected primary health care clinics or at the ANC clinic of the hospital. Women interested to partake in the study are screened according to inclusion and exclusion criteria, and referred to $\mathrm{RMMCH}$ ANC clinic for signing informed consent and data collection if eligible.

The inclusion criteria applied during recruitment screening are: 1) Confirmed pregnancy and planning to deliver her baby at RMMCH; 2) < 18 weeks' gestational age; 3) Born in South Africa, Lesotho, Swaziland, Zimbabwe, Botswana or Namibia and has been living in South Africa for at least 12 months; 4) Able to communicate effectively in one of the following languages: English, Afrikaans, Sotho, Zulu or Xhosa.

The exclusion criteria are 1) $<18$ and $>39$ years; 2) Multiple pregnancy; 3) Using illicit drugs (self-confessed); 4) Smoking (current and/or in past year); 5) Known non-communicable disease (NCD) namely diabetes, renal disease, high cholesterol, and hypertension; 6) 
Known infectious disease namely tuberculosis and hepatitis; 7) Known serious illness namely cancer, lupus or psychosis.

Even though women with infectious disease are excluded, women who are HIV positive are still included. Due to the high prevalence of HIV in the country (36\% of women aged 30-34 years [31]), their inclusion will make generalisation to the wider South African population a possibility.

\section{Recruitment and consent procedures}

Consecutive sampling is applied, thus, all accessible pregnant women at the recruitment sites may form part of the sample, if they meet the inclusion and exclusion criteria, arrive at study site on their booked date and sign informed consent. All pregnant women in the waiting areas of the ANC clinics are informed about the study. Those interested, receive a study information leaflet and are screened for eligibility individually in a private space upon which a booking date is supplied if eligible. The informed consent form is given to the participant to read, consider and discuss with her partner and/or family. Upon arrival at $\mathrm{RMMCH}$ on the booked date, the trained fieldworkers explain the informed consent form in local languages and all are given the opportunity to ask questions. All are assured that participation is voluntary and that participation or non-participation in the study will not affect their clinical care. All research participants provide written informed consent before data collection. Written informed consent is again obtained before infant assessments at 6 weeks postnatally.

\section{Data collection}

Figure 2 summarises the measurements and time points of data collection throughout the project. There are eight data collection time points (here forth referred to as phases). All data are collected either by health professionals on site or by trained fieldworkers. Phase 1 data are collected at $<18$ weeks' gestation (as confirmed by

\begin{tabular}{|c|c|c|c|c|c|c|c|c|}
\hline \multirow{3}{*}{$\begin{array}{l}\text { Assessment of: } \\
M=\text { Mother } \\
B=\text { Baby }\end{array}$} & \multicolumn{2}{|c|}{ Pregnancy } & \multirow{3}{*}{$\begin{array}{c}\text { Phase } 3 \\
\text { 36 wks } \\
( \pm 12 d) \\
\downarrow\end{array}$} & \multirow{3}{*}{$\begin{array}{l}\text { Birth } \\
\text { Phase } 4 \\
\text { Birth } \\
\qquad\end{array}$} & \multirow{3}{*}{$\begin{array}{c}\text { Phase } 5 \\
\begin{array}{c}\mathbf{6} \text { wks pp } \\
(6+2 \text { wks }) \\
\downarrow\end{array}\end{array}$} & \multicolumn{2}{|l|}{ Infancy } & \multirow{3}{*}{$\begin{array}{c}\text { Phase } 8 \\
\mathbf{1 2} \text { mo pp } \\
(52 \text { wks }+30 \text { d) }\end{array}$} \\
\hline & $\begin{array}{l}\text { Phase } 1 \\
<18 \text { wks }\end{array}$ & $\begin{array}{l}\text { Phase } 2 \\
\mathbf{2 2} \mathbf{w k s} \\
( \pm 12 \mathrm{~d})\end{array}$ & & & & $\begin{array}{c}\text { Phase } 6 \\
\mathbf{6} \text { mo pp } \\
(24 w k s+30 d)\end{array}$ & $\begin{array}{c}\text { Phase } 7 \\
\mathbf{6} \mathbf{m o} \mathbf{p p}+\mathbf{6} \text { wks } \\
( \pm 3 d)\end{array}$ & \\
\hline & & $\downarrow$ & & & & $\downarrow$ & $\downarrow$ & \\
\hline Informed consent & $x_{M}$ & - & $\mathbf{x}_{\mathrm{M}, \mathrm{B}}$ & - & - & - & - & - \\
\hline Medical assessment/history & $x_{m}$ & $x_{m}$ & $x_{m}$ & $\mathrm{x}_{\mathrm{M}, \mathrm{B}}$ & $\mathrm{x}_{\mathrm{M}, \mathrm{B}}$ & $x_{B}$ & $x_{\mathrm{B}}$ & $\mathrm{x}_{\mathrm{B}}$ \\
\hline Blood pressure & $x_{m}$ & $x_{m}$ & $x_{m}$ & - & $x_{m}$ & $x_{m}$ & - & $\mathrm{X}_{\mathrm{M}, \mathrm{B}}$ \\
\hline Socio-economics \& -demographics & $x_{m}$ & - & - & - & - & - & - & - \\
\hline Ultrasound screen & $\mathrm{x}_{\mathrm{M}, \mathrm{B}}$ & $\mathrm{x}_{\mathrm{M}, \mathrm{B}}$ & $\mathrm{x}_{\mathrm{M}, \mathrm{B}}$ & - & - & - & - & - \\
\hline Anthropometry & $x_{M}$ & $x_{m}$ & $x_{m}$ & $\mathrm{x}_{\mathrm{M}, \mathrm{B}}$ & $\mathrm{x}_{\mathrm{M}, \mathrm{B}}$ & $\mathrm{x}_{\mathrm{M}, \mathrm{B}}$ & $\mathrm{x}_{\mathrm{M}, \mathrm{B}}$ & $x_{M, B}$ \\
\hline Quantitative food frequency questionnaire (QFFQ) & $\mathrm{x}_{\mathrm{M}}$ & - & $x_{m}$ & - & - & - & - & - \\
\hline Food frequency questionnaire (infant) & - & - & - & - & - & $\mathrm{X}_{\mathrm{B}}$ & - & $\mathbf{x}_{\mathrm{B}}$ \\
\hline 24h-recall & $x_{M}$ & $x_{m}$ & $x_{m}$ & - & - & $\mathrm{X}_{\mathrm{M}, \mathrm{B}}$ & - & - \\
\hline Feeding practices questionnaire & - & - & - & - & $x_{B}$ & $\mathrm{x}_{\mathrm{B}}$ & $x_{B}$ & $\mathrm{x}_{\mathrm{B}}$ \\
\hline Food insufficiency and insecurity questionnaire & $\mathrm{x}_{\mathrm{M}}$ & - & - & - & - & $\mathrm{x}_{\mathrm{M}}$ & - & $\mathrm{x}_{\mathrm{M}}$ \\
\hline Multidimensional Assessment of Fatigue (MAF) & $x_{M}$ & $\mathrm{x}_{\mathrm{m}}$ & $x_{m}$ & - & $x_{M}$ & $\mathrm{x}_{\mathrm{M}}$ & - & $x_{M}$ \\
\hline Edinburgh Postnatal Depression Scale (EPDS-10) & $\mathrm{x}_{\mathrm{m}}$ & $x_{m}$ & $\mathrm{x}_{\mathrm{m}}$ & - & $x_{m}$ & $\mathrm{x}_{\mathrm{m}}$ & - & $x_{m}$ \\
\hline Psychomotor \& socio-emotional development & - & - & - & - & - & $\mathbf{X}_{\mathrm{B}}$ & - & $\mathrm{x}_{\mathrm{B}}$ \\
\hline ISAAC allergy questionnaire & $\mathrm{x}_{\mathrm{m}}$ & $\mathrm{x}_{\mathrm{m}}$ & $x_{m}$ & - & - & - & $x_{m}$ & - \\
\hline CAIR allergy questionnaire (infant) & - & - & - & - & - & - & $\mathbf{x}_{\mathrm{B}}$ & $x_{B}$ \\
\hline Morbidity (symptoms diary) & $\mathrm{x}_{\mathrm{m}}$ & $x_{m}$ & $x_{m}$ & $x_{m}$ & $x_{B}$ & $x_{\mathrm{B}}$ & $x_{\mathrm{B}}$ & $x_{B}$ \\
\hline Oral glucose tolerance test & - & $x_{m}$ & - & - & - & - & - & - \\
\hline Delivery and newborn assessment & - & - & - & $\mathrm{x}_{\mathrm{M}, \mathrm{B}}$ & - & - & - & - \\
\hline Cord blood sample & - & - & - & $x$ & - & - & - & - \\
\hline Blood sample & $x_{m}$ & $x_{m}$ & $x_{m}$ & $x_{m}$ & - & $\mathrm{X}_{\mathrm{M}, \mathrm{B}}$ & $x_{B}$ & $x_{B}$ \\
\hline Urine sample & $x_{m}$ & $x_{m}$ & $x_{m}$ & - & - & $\mathrm{x}_{\mathrm{M}, \mathrm{B}}$ & $x_{B}$ & $x_{B}$ \\
\hline Rectal swab & - & - & - & $\mathrm{x}_{\mathrm{M}, \mathrm{B}}$ & - & $\mathrm{X}_{\mathrm{M}, \mathrm{B}}$ & - & $\mathrm{x}_{\mathrm{B}}$ \\
\hline Breast milk sample & - & - & - & - & $x_{m}$ & $\mathrm{x}_{\mathrm{M}}$ & - & - \\
\hline Skin prick test & - & - & - & - & - & - & $\mathbf{x}_{\mathrm{M}, \mathrm{B}}$ & $\mathrm{X}_{\mathrm{B}}$ \\
\hline \multicolumn{9}{|c|}{$\begin{array}{l}\text { Fig. } 2 \text { Data collection per phase during the NuPED study. Prenatal data collection time points are at }<18 \text { weeks' gestation (phase } 1 \text { ); } \pm 22 \text { weeks' } \\
\text { gestation (phase } 2) ; \pm 36 \text { weeks' gestation (phase } 3 \text { ) and at birth (phase 4). Postnatal data collection time points are at infant postnatal age of } 6 \text { weeks } \\
\text { (phase } 5) ; 24 \text { weeks (phase } 6) ; 6 \text { weeks post measles immunisation ( } \pm 3 \text { days) (phase } 7 \text { ) or } 30 \text { weeks ( } 30 \text { days) if measles immunization was not given } \\
\text { between } 24 \text { and } 28 \text { weeks; and } 52 \text { weeks ( }+30 \text { days) (phase } 8 \text { ). wks, weeks; d, days, pp, postpartum }\end{array}$} \\
\hline
\end{tabular}


obstetric ultrasound). These data will supply information on the nutritional status of women early in their pregnancy. It is important to note that in Johannesburg only $45 \%$ of women access ANC before 20 weeks gestation and only $23 \%$ in their first trimester (as reported from other urban areas) [30]. Thus, for practical purposes, the early pregnancy window was set at $<18$ weeks' gestation. Phase 2 data are collected at 22 weeks' gestation (window \pm 12 days) when anomaly ultrasounds are typically scheduled. Phase 3 data are collected at 36 weeks' gestation (window \pm 12 days). Study midwifes and/or fieldworkers collect birth data (phase 4) within a window of $12 \mathrm{~h}$. Postnatal data are collected at 6 weeks (+14 days) (phase 5); 24 weeks (+ 30 days) (phase 6); 6 weeks post measles immunisation ( \pm 3 days) (phase 7 ) or 30 weeks $(+30$ days) if measles immunization was not given between 24 and 28 weeks; and 52 weeks (+ 30 days) (phase 8) postnatal age. The purpose of the phase 7 data collection point specifically is to assess measles immunoglobulin G $(\operatorname{Ig} G)$ as marker of response to immunisation at 6 months and immune function.

\section{Maternal socio-economics and-demographics}

Socio-economic and -demographic data are collected at phase 1 by means of a structured interview. Data include date and country of birth, marital status, educational level, home language, employment status, household income, number of members in the household, and beneficiaries of social grants. Lastly, living standards data are obtained to allow classification according to the Living Standards Measure (LSM) developed by the South African Audience Reference Foundation (SAARF) [32]. This measure is widely used in South Africa to describe the socio-economic status of the population [33].

\section{Maternal household food insufficiency and insecurity}

The level of the participating women's household food insufficiency and insecurity is assessed at phase 1 in pregnancy and again at phases 6 and 8 postnatally. In a structured interview, women are asked questions on food insecurity and child hunger using the Community Childhood Hunger Identification Project (CCHIP) index [34] that was also used to determine the status of food security in previous national surveys in South Africa [35]. Furthermore, women were asked a validated, single-item question on food insufficiency -"How many days in the past week have you gone hungry? By this I mean days when you felt you didn't have enough to eat."-that was previously used to determine food insufficiency in pregnant women in South Africa [36].

\section{Maternal dietary intake}

Maternal dietary intake data are obtained by means of two dietary assessment methods, namely the 24-h recall
(24-HR) and a quantified food frequency questionnaire (QFFQ). Both methods are interviewer administered by using standardised probing questions [37]. Standard measuring equipment, common size containers (e.g. cups, bowls and glasses) as well as two- and three-dimensional food models are being used to assist in quantifying portion sizes.

A single 24-HR, which obtains details about nutritional supplement use as well, is administered at phases 1,2 and 3 in pregnancy, as well as at 6 months postnatally (phase 6). Each participant is requested to recall all foods and drinks consumed the previous day from when she woke up until the next day the same time. The recall is done chronologically unless the participant wishes to recall randomly. The purpose of the single $24-\mathrm{HR}$ is to describe the average intake of the group [38]. All supplement use, as well as food cravings and aversions, are additionally recorded daily by participants on a calendar.

The second dietary assessment method, the QFFQ, is completed at phases 1 and 3 . It was validated for the population in the Transition and Health during Urbanisation of South Africans (THUSA) study [39] and its reproducibility was proven $[40,41]$. It was also used previously to assess individual and total omega-3 and omega- 6 fatty acid intake in a rural and urban South-African population [42]. This QFFQ includes a list of typically consumed foods and minor changes were made to the questionnaire according to vernacular used by the study population in that particular area. Participants are asked according to the $\sim 140$ food items listed in the QFFQ, the type/brand, cooking methods, frequency and the amount of all food and drink consumed in the past 4 weeks.

For the QFFQ data, portion sizes are converted to grams per week per food item, by two registered dietitians/ nutritionists. For the 24-HR all portion sizes are converted to grams per day per food item. The resources to assist with this include the Condensed Food Composition Tables for South Africa [43] and the South African Medical Research Council (SAMRC) Food Quantities Manual [44].

\section{Maternal anthropometric measurements}

Maternal weight and mid-upperarm circumference (MUAC) are obtained at each phase (1 to 8 ), and height only at phase 1 and 5. All measurements are done twice and recorded to the nearest $0.05 \mathrm{~kg}$ for weight, $0.1 \mathrm{~cm}$ for MUAC and height. Standardised methods of the International Society for the Advancement of Kinanthropometry [45] are used with a calibrated digital scale for weight, a mobile stadiometer for height; and non-stretchable metal measuring tape for MUAC.

\section{Maternal medical assessment and history}

Medical history is obtained at each prenatal visit (phases 1 to 3 ) by means of participant responses and inspection 
of medical files. Information includes medication use (including vaccines), HIV status, obstetric history, hospital admission during pregnancy, use of alcohol, and exposure to passive smoking. At the first postnatal visit (phase 6) a follow-up is made on the maternal medical history at birth. Blood pressure is measured at each prenatal visit (phases 1 to 3 ) as well as postnatally (phases 5, 6 and 8) according to international guidelines [46] using calibrated equipment. Appropriate sized cuffs are used for obese participants.

Standard procedures are used for a 2-h $75 \mathrm{~g}$ oral glucose tolerance test (OGTT) between 24 and 28 weeks gestation to determine development of gestational diabetes mellitus [47].

\section{Maternal morbidity}

Maternal morbidity symptoms are assessed from enrolment to birth using a daily calendar. Mothers are instructed on how to complete the calendar and to return completed calendars at each visit. The infectious morbidity symptoms assessed are fever, headache, diarrhoea, nasal discharge and coughing. Other possible pregnancy-related symptoms included are constipation, nausea, vomiting, extreme tiredness and heartburn. Any medication and supplementation use is also recorded daily.

\section{Maternal allergy assessment}

The International Study for Asthma and Allergies in Childhood (ISAAC) questionnaire [48] is used to assess allergy symptoms in maternal participants at phases 1 to 3 during pregnancy, and 7 postnatally. Additionally, skin prick tests for common allergens are used at phase 7 postnatally to assess sensitisation [49]. The questionnaire is designed to assess rhinitis, asthma and eczema in children and has been used successfully in an older black population in South Africa [50]. A positive score on any of these three symptoms indicates an allergic phenotype.

Maternal skin prick tests are performed by a medical doctor according to the procedure described in the $\mathrm{Al}$ lergy Society of South Africa's position statement on skin prick testing [49]. In mothers, sensitisation to a house dust mite mixture including Dermatophagoides farinae, as well as German cockroach, mould mixture, cat and dog dander, maize pollen, Bermuda grass and Quercus robur (English oak), Eucalyptus, Cypressus arizonica (Arizona cypress), Platanus hybrida (London plane) and Acacia trees are measured. A diagnosis of 1) sensitised with clinical symptoms, 2) sensitised and clinically tolerant, 3) sensitised and unknown clinical reactivity, 4) not sensitised with clinical symptoms, 5) unknown sensitization with clinical symptoms or 6) not sensitized with no clinical symptoms is made. The mother is given medical advice and referred if necessary.

\section{Maternal depression and fatigue}

Perinatal depression is assessed at phases 1 to 3 during pregnancy and at phases 5,6 and 8 postnatally using the Edinburgh Postnatal Depression Scale (EPDS). The EPDS is a 10-item scale assessing depressive symptoms experienced in the past 7 days [51], which has been validated for assessing perinatal depression in African settings, including South Africa [52]. Maternal fatigue is assessed at the same time points using the Multidimensional Assessment of Fatigue (MAF) scale, which was shown to be a reliable and valid measure of fatigue in pregnant and postpartum women [53]. Both questionnaires are interviewer administered.

Foetal ultrasonography: Gestational age and foetal growth Foetal ultrasonography examination is carried out by an obstetrician at the first data collection time point to confirm gestation. Estimation of foetal crown rump length and/or biparietal diameter or femur length between 6 and 18 weeks' gestation indicates an accuracy within 5-7 days [54]. Foetal crown-rump length is used to determine gestational age of participants in their first trimester [55]. For participants in their second trimester, a combination of multiple biometric parameters (biparietal diameter, head circumference, abdominal circumference, and femur length) are used to determine gestational age [55]. Ultrasound is also used to determine the number of foetuses and confirm foetal movement, as well as foetal growth at 22 and 36 weeks' gestation (phases 2 and 3).

\section{Birth and neonatal assessments}

Maternal data collected at birth (phase 4) are obtained from maternal medical files and include hospital admission and discharge dates and times, mode of delivery, induction/augmentation of delivery, type of anaesthetic or pain relief if any, rapid plasma reagin (RPR) status (indicative of syphilis infection), HIV status, rhesus negative status and presence of maternal diabetes mellitus. If the delivery is induced or caesarean section conducted, the reason for this intervention is obtained. The study nurses obtain maternal weight before birth with a calibrated digital scale.

Neonatal data collected at birth from the medical file include date and time of birth, gender, Apgar score (at 1 and $5 \mathrm{~min}$ ) [56], vital signs, medical interventions required, foetal distress and presence of meconium stained liquor. Four identically trained study nurses obtain newborn anthropometry (weight, midarm circumference (MAC), crown-heel length (CHL), head circumference (HC) and thoracic circumference (TC)) within $12 \mathrm{~h}$ of birth [57]. If the measurements cannot be taken by the study nurses, hospital records are used to obtain anthropometrical data (using the same calibrated infant scale). 
Newborn weight is measured with a calibrated digital infant scale to the nearest $10 \mathrm{~g}$. In order to minimize intra-observer variability all circumferences and CHL are measured with an inelastic tape to the nearest $0.5 \mathrm{~cm}$ (metal measuring tape not used to prevent possible lacerations). CHL is measured by placing the newborn in supine position on the tape measure on a flat surface with all limbs extended and measurement taken from vertex to heel of foot, with foot held in a perpendicular position to the leg.

\section{Infant dietary intake and feeding practices}

Data on infant feeding practices are collected at each postnatal phase (5 to 8 ). Mothers are asked how soon after birth the infant was breastfed, if the infant is currently being breastfed and if not, the duration of breastfeeding. All mothers are asked details about any other food or drink (including infant formula, medicine and supplements) given to the infant.

An unquantified food frequency questionnaire for the infant is administered at phases 6 and 8 for qualitative assessment (types and frequency) of milk and complementary feeding at 6 and 12 months postnatally. An adapted questionnaire previously used in the South African context is used [58]. Frequency of the type of food eaten during the past month can be reported by the mother as every day; most days (not every day, but at least 4 times per week); once a week (less than 4 times per week, but at least once per week) or never.

A single 24-HR for the infant is administered at phase 6 for quantitative assessment (macro- and micronutrient intakes) of intakes at 6 months postnatally. Similar methods and aids are used as described for maternal dietary intake. However, smaller bowls and different sizes of small spoons are used for infant dietary intake to ease realistic reporting for the mother. Also, emphasis is placed on dished food not eaten and the amount left in the bowl to ensure actual intake is reported.

\section{Infant anthropometric measurements}

Infant growth is assessed at each postnatal visit. Before measurements are taken, the infant is assessed for presence of oedema. The infant is weighed on a calibrated scale with minimum of clothing, namely only a vest, and without a nappy; and recorded to the nearest $5 \mathrm{~g}$.

Recumbent length of the infants is taken by means of an infantometer to the nearest $0.1 \mathrm{~cm}$. All foot and headwear is removed before measurements are taken. The measurement is taken with the infant lying on his/her back on the infantometer, legs extended with the head and foot board making contact with the infant.

\section{Infant medical assessments}

A medical doctor performs a general and physical medical assessment of infants at each postnatal visit. The infant assessment includes HIV status history and a general, ear, nose and throat, respiratory, cardiovascular, abdominal and neurological examination as well as any current complaints. It also includes a medical plan for the infant.

\section{Infant morbidity}

Infant morbidity assessment is performed at each postnatal visit by a medical doctor with a structured questionnaire. A morbidity calendar, kept daily by the mother/ caregiver, is used as reference. The calendar and symptoms are explained to the mother at birth and each postnatal visit up to phase 7 , whereby each new section of the calendar is handed to the mother for return at the next visit. Symptoms assessed are fever, diarrhoea, vomiting, nasal discharge, coughing, diaper and other rash. Any unscheduled visits to a medical facility and medicine given to the infant are also recorded. The medical doctor diagnoses and determines the duration of each morbidity event using the structured questionnaire with reference to the morbidity calendar.

\section{Infant allergy assessment}

A medical doctor assesses the allergy phenotype and sensitisation of infants with the Childhood Allergy and Immunology Research (CAIR) questionnaire and skin prick tests at phases 7 and 8 postnatally. The CAIR questionnaire was developed by the School of Paediatrics and Child Health of the University of Western Australia and is designed to assess asthma, rhinitis and eczema in infants.

Infant skin prick tests are performed at phases 7 and 8 by a medical doctor according to the procedure described in the Allergy Society of South Africa's position statement on skin prick testing [49]. Skin prick tests to determine sensitisation to common allergens are common medical practice in infants older than 4 months $[59,60]$. In infants, sensitization to a house dust mite mixture including Dermatophagoides farinae, German cockroach, mould mixture, cat and dog dander, maize pollen, Bermuda grass, chicken egg, cow's milk, cod fish, peanuts, wheat and soy bean flour and potato are measured. A diagnosis of 1) sensitised with clinical symptoms, 2) sensitised and clinically tolerant, 3) sensitised and unknown clinical reactivity, 4) not sensitised with clinical symptoms, 5) unknown sensitization with clinical symptoms or 6) not sensitized with no clinical symptoms is made. The infant's medical plan is managed accordingly.

\section{Infant immune response}

The infant's IgG response to measles immunisation is assessed at phase 7, which is 6 weeks after measles immunisation was administered at the study site. The measles immunisation in South Africa forms part of the National Expanded Programme for Immunisation and permission to administer it at the study site has been 
granted by the Department of Health of Gauteng Province and the City of Johannesburg. Response to an immunisation is regarded as a good marker to measure immune function in vivo [61] and the response will be in the log phase 6 weeks after immunisation, which is the most sensitive stage to measure differences in response among infants.

\section{Infant psychomotor and socio-emotional development}

Psychomotor and socio-emotional development of the offspring is being assessed using the Protocol for Child Monitoring -Infant version (PCM-I), which combines both parental report and direct observation by trained assessors to provide a comprehensive evaluation of a child's motor skills, cognition, language, personal and socio-emotional development [62]. The PCM-I consists of items derived from: 1) the Kilifi Developmental Inventory (KDI) [63], previously used by the investigators to determine psychomotor development in an infant population in South Africa [64], 2) the Developmental Milestone Checklist (DMC-II) [65, 66], and 3) the Profile of Social-Emotional Development (PSED), which is based in part on the Brief Infant/Toddler Social Emotional Assessment [67].

\section{Biological sample collection}

Venous blood $(42 \mathrm{ml})$ is drawn from the participating women into labelled EDTA-coated, serum and trace element free evacuated tubes at phases 1-4 during pregnancy and at phase 6 postnatally. At birth (phase 4), umbilical cord blood samples are taken immediately after the separation of the newborn from the umbilical cord and before placental delivery into labelled EDTA-coated, serum and trace element free evacuated tubes. Venous blood from the infant $(3 \mathrm{ml})$ is drawn at phases 6,7 and 8. Dry blood spots are collected on filter paper cards (Whatman, Inc) immediately after blood collection (maternal, cord and infant). The filter paper cards are allowed to dry at room temperature for $24 \mathrm{~h}$, placed in ziplock bags with desiccants, and stored at $-20{ }^{\circ} \mathrm{C}$ until analysis. In case venous blood cannot be obtained from the infants, capillary blood is being collected by foot venepuncture.

Venous blood is processed within $1 \mathrm{~h}$ after blood draw; plasma/serum separated and red blood cells washed twice with normal saline. Buffy coats are stored in 1:1 vol: vol RNA later (Ambion).

Midstream spot urine samples $(5 \mathrm{ml})$ are collected from the participating women at phases 1,2 and 3 during pregnancy and at phase 6 postnatally into a urine collection cup. From the infants, a $2-5 \mathrm{ml}$ urine sample is collected at phases 6,7 and 8 using adhesive paediatric urine collection bags. Urine samples are transferred into labelled microtubes and stored at $-20{ }^{\circ} \mathrm{C}$ within $4 \mathrm{~h}$.

Breast milk samples (fore-milk) are collected from lactating mothers at phases 5 and 6 as described previously [68].

Rectal swabs (FLOQSwab, COPAN) are collected from both the mother and the baby at phases 4 and 6 of data collection. The mucosal microbe sample is taken approximately $\pm 3 \mathrm{~cm}$ into the anal canal, beyond the anal verge. After collection the cotton bud end of the swab with the collected sample is immediately preserved in RNAlater (Ambion) and stored at $-20{ }^{\circ} \mathrm{C}$.

Biological samples are processed on site and stored at $-20{ }^{\circ} \mathrm{C}$ for a maximum of 14 days. Thereafter, frozen samples are transported to the North-West University for storage at $-80{ }^{\circ} \mathrm{C}$ until analysis. Storage temperature is monitored and logged for the entire duration of the study.

\section{Biochemical analyses}

Haemoglobin is determined on site in whole blood $(20 \mu \mathrm{L})$ using HemoCue (Hb 201+, Ängelholm, Sweden). The iron status indices, ferritin and transferrin receptor, as well as the vitamin A status indicator retinol binding protein will be determined using the Q-Plex ${ }^{\mathrm{Tu}}$ Human Micronutrient Array (7-plex, Quansys Bioscience, Logan, UT, USA) [69]. This multiplex immune-assay also includes the acute phase proteins $\mathrm{C}$-reactive protein (CRP) and alpha1-acid glycoprotein (AGP), as well as the malaria marker HRP2 and thyroglobulin, which is a marker of iodine status. Urinary iodine concentrations are determined in spot urine samples using a modification of the Sandell-Kolthoff reaction with spectrophotometric detection [70]. Vitamin A and E status will be determined using high pressure liquid chromatography (HPLC) and ultraviolet light detection [71]. Vitamin D status will be determined by measuring total 25 -Hydroxyvitamin D $[25(\mathrm{OH}) \mathrm{D}]$ concentrations in serum using liquid chromatography tandem mass spectrometry (LCMSMS) [72]. Fatty acids in red blood cell total phospholipids are determined using gas chromatography tandem mass spectrometry (GCMSMS) [73]. Zinc concentrations are determined in serum using atomic absorption spectrometry [74].

Thyroid hormones (thyroid stimulating hormone, thyroglobulin, total thyroxine) will be determined in whole blood spots by using electrochemiluminescence immunoassays. Lipid-derived immune modulators will be determined with LCMSMS [75]. Cytokines and hepcidin will be determined using ELISA.

Kynurenine pathway metabolites (mediates interactions between immunological and neurological function) will be determined using LCMSMS [76]. Brain-derived neurotrophic factor (BDNF) as a potential marker of neuronal growth and differentiation will be determined using ELISA [77]. 
Gut microbiome profiling will be done by isolating microbial DNA from the collected rectal swabs using Qiagen Stool minikit and analysing the 16S rRNA genes DNA sequences on the Ion Torrent $16 \mathrm{~S}$ metagenomics solution offered by ThermoFisher Scientific.

Targeted epigenetic marks, specifically DNA methylation signatures, will also be assessed in the context of the primary and secondary outcomes of this study. Gene specific DNA methylation will be assessed using the Qiagen EpiTech system. Both, the EpiTect Methyl II Signature and EpiTect Methyl II Complete PCR Arrays (Qiagen) will be considered.

Targeted genotyping of genes of interest in the context of fatty acid, lipid and micronutrient metabolism will also be investigated following the Ion AmpliSeq Targeted Sequencing approach using the Ion Chef $f^{m}$ and Ion $S 5^{\mathrm{ma}}$ Systems (ThermoFisher).

\section{Data management and analysis \\ Sample size calculation}

The number of participants to sample has been calculated using the $G^{*}$ Power 3.1.9.2 statistical programme [78]. The statistical calculation involved is the linear multiple regression: fixed model, single regression coefficient. The calculation was based on a small effect size $\mathrm{F}^{2}$ of 0.05 ; probability of error (alpha) of 5\%; a power of $80 \%$ and ten predictors on the birth outcome "low birth weight". The result was that 196 participants will be required. Taking into consideration that participants may opt out of the project (at $25 \%$ rate), it is calculated that a minimum of 245 participants should be recruited. We intended to recruit a minimum of 250 participants. However, should the researchers be able to obtain additional funding, additional participants may be included.

\section{Data management}

Data are managed by two dedicated data managers. Raw data are captured and saved in password protected Microsoft Access documents with passwords known only to the operator responsible for data imputing and the principal investigators. A second person checks $20 \%$ of all the captured data randomly and notes and corrects any errors. If there are more than $5 \%$ errors, respective data are re-captured. The final version of the database will be stored under protected zipped files. Data are collected on dual core electronic archives with automatic backup. Information of the single datasets are stored using anonymous IDs. The document linking anonymous IDs to participants will be collected and stored separately.

Dietary data are captured in Microsoft Excel (Microsoft Corporation, Washington, USA) and all electronic entries are double checked by a registered dietitian for the correct food code and a reasonable amount reported. Analyses will be done by the SAMRC by linking data to the most recent food composition database. Data will then be screened by means of range checks and for outliers in total energy, protein, fat, vitamin $\mathrm{A}$ and vitamin $\mathrm{C}$ intake.

\section{Data analysis}

Overall, data processing and statistical analysis are performed using the SAS statistical package (SAS, Cary, NC, USA). Analysis of baseline (phase 1) data will be conducted to describe the nutritional status and basic socio-economic characteristics of the pregnant women. Data will be tested for outliers and normality by means of Q-Q plots and histogram visual inspection. Test for normality will be performed by the Shapiro-Wilk test. Normally distributed data will be expressed as means $\pm \mathrm{SD}$; non-normally distributed data will be expressed as medians (25th percentile, 75th percentile).

Data will be analysed cross-sectionally to determine associations between variables at each time point by using appropriate statistical methods (e.g. multiple linear regression analysis, ANCOVA, logistic regression analysis), adjusting for potential covariates.

Data will be analysed prospectively to determine associations between variables at different time points (longitudinally) by using appropriate statistical methods (e.g. linear mixed effects models), adjusting for potential time-dependent and static covariates.

Data will also be analysed retrospectively in matchedcontrol sub-studies by determining associations between observed outcomes and variables collected at previous time points.

The level of significance will be set at $P<0.05$.

\section{Discussion}

The importance of perinatal nutrition and its role in offspring health, is recognised [79]. Nutrition during pregnancy is an important factor associated with both maternal and infant health outcomes [80]. To date, however, South African public health nutrition interventions for pregnant women are limited to folic-iron and calcium supplementation, while it is highly likely that the diet of pregnant women living in South Africa is lacking vital micronutrients and essential fatty acids beyond those supplied, or is even containing excessive amounts of specific micro- and macro-nutrients. In order to advocate evidence-based healthcare policy and practice, the identification of nutrient deficiencies and poor eating patterns of pregnant women in South Africa, which are associated with adverse neonatal outcomes and delayed early offspring development, is imperative.

Little is known about the dietary behaviour and nutritional status of pregnant women living in South Africa. To the best of our knowledge, this is the first South African study focusing on the assessment of both maternal 
dietary intake and nutritional status in women pre- and postnatally and to investigate associations with outcomes of maternal and infant health. This study is novel due to the comprehensive set of nutrition related data and indicators of maternal and infant health being obtained in a South African setting. Therefore, this explorative project will contribute to identifying factors that may be targeted in future pre- and/or post-conception maternal interventions for optimal offspring development and possibly reduction in adult NCD risk.

This study also has its challenges. The inclusion and exclusion criteria for participants were designed as such to obtain a sample of generally healthy women, who are able to speak the local language and who could be followed-up from early pregnancy until the infants are 12 months old. South African statistics show that only $52 \%$ of women attend antenatal care before 20 weeks' gestation [30], thus access to women early in pregnancy is restricted and limits enrolment into the study. Furthermore, many healthcare facilities in Johannesburg serve a predominantly migrant population [81] posing a challenge for longitudinal data collection. Additionally, these women may choose to eat traditional foods [82] that do not form part of the South African Food Database for nutritional analysis; and may not be able to speak a local language [83] hampering detailed reporting during dietary assessments. Thus, migrating women or those unable to speak local languages could not be included in the study.

A limitation of the study is that women who fit the inclusion criteria are invited to join the study by visiting the data collection site at an agreed date. Having this option of attending may contribute to self-selection bias. Our recruitment data to date indicate that of those invited to take part in the study; only approximately $50 \%$ arrive at the data collection site on the booked date.

Even so, this study will provide a comprehensive and unique database from an urban South African setting which will allow for cross-sectional, prospective and retrospective analyses to describe the nutritional status and dietary intake of pregnant women, and to determine associations with health outcome measures. These results will supply context to intervention studies with the aim to improve maternal as well as offspring health in South Africa.

\footnotetext{
Abbreviations

24-HR: 24-h recall; AGP: Alpha1-acid glycoprotein; ANC: Antenatal care; BDNF: Brain-derived neurotrophic factor; CHL: Crown-heel length; CRP: C-reactive protein; DOHaD: Developmental Origins of Health and Disease; ELISA: Enzyme-linked immunosorbent assay; ESRU: Empilweni Services and Research Unit; GC-MS/MS: Gas chromatography-mass spectrometry; HC: Head circumference; HPLC: High-performance liquid chromatography; HRP2: Histidine-rich protein 2; MAC: Mid-arm circumference; MUAC: Mid-upper arm circumference; NCD: Non-communicable disease; NuPED study: Nutrition during pregnancy and early development study; OGTT: Oral glucose tolerance test; QFFQ: Quantified food frequency questionnaire; RMMCH: Rahima Moosa Mother and Child Hospital; RPR: Rapid plasma reagin; SD: Standard deviation; TC: Thoracic circumference
}

\section{Acknowledgements}

We appreciate and acknowledge the inputs and involvement of Prof A Coovadia, Prof H Lombaard, Dr. AJ Wise, Dr. E Loock, Dr. R Adams, Dr. R Strehlau, Prof M Faber, Dr. S Sotunde, Dr. M Rothman, Ms. M Bezuidenhout, the ESRU team; and thank the sonographers and nurses of RMMCH, the nurses at the primary healthcare clinics, the fieldworkers, midwifes and all the participants.

\section{Funding}

This work is based on the research supported in part by the National Research Foundation of South Africa for the grant, Unique Grant No. 99374 and the South African Medical Research Council under a Self-Initiated Research Grant. The work has further financial support from the University of South Africa's Research Department for the grant Academic Qualification Improvement Programme.

None of the funders played a role in the design of the study; data collection, analysis, and interpretation, or in writing the manuscript. The views and opinions expressed are not those of the funders.

\section{Availability of data and materials}

Data sharing is not applicable to this article as no datasets were generated or analysed for the purposes of this protocol article.

\section{Authors' contributions}

EAS, JB, LM, LZ and CMS conceptualised and designed the study. EAS, JB, LM and $L Z$ are implementing the research. $L M$ and $L Z$ are responsible for laboratory analyses. JB, LM and RC are responsible for data capturing and analyses. EAS drafted the paper with equal contributions from JB, LM, LZ and CMS. All authors read and approved the final manuscript.

\section{Ethics approval and consent to participate}

The Human Research Ethics Committees of the North-West University, Potchefstroom (NWU-00186-15-A1 and NWU-00049-16-A1) and the University of Witwatersrand, Johannesburg (M150968 and M161045) provided ethical approval for the study. Permission to conduct the research in the relevant clinical setting was obtained from the Gauteng Health Department, City of Johannesburg District Research Committee and the Clinical Manager of Rahima Moosa Mother and Child Hospital.

All participants sign written informed consent before data collection.

\section{Consent for publication}

Not applicable.

\section{Competing interests}

The authors declare that they have no competing interests.

\section{Publisher's Note}

Springer Nature remains neutral with regard to jurisdictional claims in published maps and institutional affiliations.

Received: 20 April 2018 Accepted: 16 July 2018

Published online: 24 July 2018

\section{References}

1. Black MM, Walker SP, Fernald LCH, Andersen CT, DiGirolamo AM, Lu C, et al. Early childhood development coming of age: science through the life course. Lancet. 2017;389:77-90

2. Barker DJP, Osmond C. Infant mortality, childhood nutrition, and ischaemic heart disease in England and Wales. Lancet. 1986;1:1077-81.

3. Barker DJP. The origins of the developmental origins theory. J Intern Med. 2007;261:412-7.

4. Barker DJP. The malnourished baby and infant. Br Med Bull. 2001;60:69-88.

5. Palmer AC. Nutritionally mediated programming of the developing immune system. Adv Nutr An Int Rev J. 2011;2:377-95.

6. Kramer MS. The epidemiology of adverse pregnancy outcomes: an overview. J Nutr. 2003;133:1592S-6S.

7. Kaiser L, Allen LH. Position of the American dietetic association: nutrition and lifestyle for a healthy pregnancy outcome. J Am Diet Assoc. 2008;108:553-61.

8. Abu-Saad K, Fraser D. Maternal nutrition and birth outcomes. Epidemiol Rev. 2010;32:5-25. 
9. Wu G, Imhoff-Kunsch B, Girard AW. Biological mechanisms for nutritional regulation of maternal health and fetal development. Paediatr Perinat Epidemiol. 2012;26(SUPPL. 1):4-26.

10. Pearce EN. Assessing iodine intakes in pregnancy: why does this matter? $\mathrm{Br}$ J Nutr. 2015;113 March:1-3. doi:https://doi.org/10.1017/S0007114515000471.

11. Ota E, Mori R, Middleton P, Mahomed K, Miyazaki C, Za B. Zinc supplementation for improving pregnancy and infant outcome (review). Cochrane Database Syst Rev. 2015; https://doi.org/10.1002/14651858.CD000230.pub.

12. Gómez T, Bequer L, Mollineda A, González O, Diaz M, Fernández D. Serum zinc levels of cord blood: relation to birth weight and gestational period. J Trace Elem Med Biol. 2015;30:180-3. https://doi.org/10.1016/j.jtemb.2014.12.009.

13. Sapin V, Alexandre MC, Chaïb $S$, Ja B, Sauvant $P$, Borel $P$, et al. Effect of vitamin a status at the end of term pregnancy on the saturation of retinol binding protein with retinol. Am J Clin Nutr. 2000;71:537-43.

14. Pina-Camacho L, Jensen SK, Gaysina D, Barker ED. Maternal depression symptoms, unhealthy diet and child emotional-behavioural dysregulation. Psychol Med. 2014;45:1851-60. https://doi.org/10.1017/ S0033291714002955.

15. Baskin R, Hill B, Jacka FN, O'Neil A, Skouteris $H$. The association between diet quality and mental health during the perinatal period. A systematic review. Appetite. 2015;91:41-7.

16. Muktabhant B, Lawrie TA, Lumbiganon P, Laopaiboon M. Diet or exercise, or both, for preventing excessive weight gain in pregnancy. Cochrane Database Syst Rev. 2015;6:1-257.

17. Statistics South Africa. Poverty trends in South Africa: An examination of absolute poverty between 2006 and 2011. Pretoria; 2014.

18. Shisana O, Labadarios D, Rehle T, Simbayi L, Zuma K, Dhansay A, et al. South African National Health and nutrition examination survey, 2012 (SANHANES-1). 2nd ed. Cape Town: HSRC Press; 2014. http://www.hsrc.ac. za/en/research-data/view/6493

19. Steyn N, Bradshaw D, Norman R, Joubert J, Schneider M, Steyn K. Dietary changes and the health transition in South Africa: Implications for health policy. Italy, Rome: Food and Agriculture Organization of the United Nations (FAO); 2006. http://www.fao.org/docrep/009/a0442e/a0442e0v.htm

20. Vorster HH, Kruger A, Margetts BM. The nutrition transition in Africa: can it be steered into a more positive direction? Nutrients. 2011;3:429-41.

21. Black RE, Victora CG, Walker SP, Bhutta ZA, Christian P, de Onis M, et al. Maternal and child undernutrition and overweight in low-income and middle-income countries. Lancet. 2013;382:427-51. https://doi.org/10.1016/ S0140-6736(13)60937-X.

22. National Department of Health (NDoH), Statistics South Africa (Stats SA), South African Medical Research Council (SAMRC), ICF. South Africa Demographic and Health Survey 2016: Key Indicators. Pretoria, South Africa and Rockville, Maryland, USA; 2017.

23. Walker SP, Wachs TD, Grantham-Mcgregor S, Black MM, Nelson CA, Huffman $\mathrm{SL}$, et al. Inequality in early childhood: risk and protective factors for early child development. Lancet. 2011;378:1325-38.

24. Kozuki N, Katz J, Lee AC, Vogel JP, Silveira MF, Sania A, et al. Short maternal stature increases tisk of small-for-gestational-age and preterm births in lowand middle-income countries: individual participant data meta-analysis and population attributable fraction. J Nutr. 2015;145:2542-50. https://doi.org/10. 3945/jn.115.216374.

25. Hall K, Sambu W, Berry L, Giese S, Almeleh C. Rosa S. Cape Town: South African Early Childhood Review; 2016. http://ilifalabantwana.co.za/southafrican-early-childhood-review-2016/

26. National Department of Health (NDoH). Guidelines for maternity care in South Africa. Pretoria, South Africa; 2015. https://www.health-e.org.za/2015/ 11/17/guidelines-maternity-care-in-south-africa/.

27. Solarin I, Black V. "They told me to come back": Women's antenatal care booking experience in inner-city johannesburg. Matern Child Health J. 2013; 17:359-67.

28. Mamabolo RL, Alberts M, Steyn NP, Delemarre-van de Waal HA, Nthangeni NG, Levitt NS. Evaluation of the effectiveness of iron and folate supplementation during pregnancy in a rural area of Limpopo province. South African J Clin Nutr. 2008;17:15-21.

29. Hoque $M$, Hoque $E$, Kader $S$. Audit of antenatal care in a rural district of KZN, South Africa. South African Fam Pract. 2008;50:66a-d.

30. Smith AM. Healthcare reform priorities for South Africa: four essays on the financing, delivery and user acceptability of healthcare by. Stellenbosch University; 2016. http://ir.nrf.ac.za/bitstream/handle/10907/505/smith healthcare_2016.pdf?sequence=1\&isAllowed=y.
31. Shisana O, Rehle T, Simbayi LC, Zuma K, Jooste S, Zungu N, et al. South African national HIV prevalence, incidence and behaviour survey, 2012. Cape Town: HSRC Press; 2014. http://repository.hsrc.ac.za/handle/20.500.11910/2490. Accessed 13 Dec 2017

32. Haupt $P$. The SAARF universal living standards measure (SU-LSM ${ }^{\mathrm{TM}}$ ): 12 years of continuous development. 2016. http://www.saarf.co.za/LSM/lsm-article.asp. Accessed 25 Jul 2017.

33. Labadarios $D$, Steyn NP, Nel J. How diverse is the diet of adult south Africans? Nutr J. 2011;10:33. https://doi.org/10.1186/1475-2891-10-33.

34. Wehler CA, Scott RI, Anderson JJ. The community childhood hunger identification project: a model of domestic hunger - demonstration project in Seattle. Washington J Nutr Educ. 1992;24:29S-35S. https://doi.org/10. 1016/S0022-3182(12)80135-X.

35. Labadarios D, Mchiza ZJ-R, Steyn NP, Gericke G, Maunder EMW, Davids YD, et al. Food security in South Africa: a review of national surveys. Bull World Health Organ. 2011;89:891-9. https://doi.org/10.1590/S0042-96862011001200012.

36. Tsai AC, Tomlinson M, Comulada WS, Rotheram-Borus MJ. Food insufficiency, depression, and the modifying role of social support: evidence from a population-based, prospective cohort of pregnant women in periurban South Africa. Soc Sci Med. 2016;151:69-77. https://doi.org/10.1016/J. SOCSCIMED.2015.12.042.

37. Shim J-S, Oh K, Kim HC. Dietary assessment methods in epidemiologic studies. Epidemiol Health. 2014;36:e2014009. https:/doi.org/10.4178/epih/e2014009.

38. Rutishauser IHE. Dietary intake measurements. Public Health Nutr. 2005:8:1100-7.

39. Maclntyre UE, Venter CS, Vorster HH, Steyn HS. A combination of statistical methods for the analysis of the relative validation data of the quantitative food frequency questionnaire used in the THUSA study. Public Health Nutr. 2000:4:45-51.

40. Maclntyre UE, Kruger HS, Venter CS, Vorster HH. Dietary intakes of an African population in different stages of transition in the north West Province, South Africa: the THUSA study. Nutr Res. 2002;22:239-56.

41. Wentzel-Viljoen E, Laubscher R, Kruger A. Using different approaches to assess the reproducibility of a culturally sensitive quantified food frequency questionnaire. South African J .... 2011;24:143-148. http://www.ajol.info/ index.php/sajcn/article/view/69592.

42. Richter M, Baumgartner J, Wentzel-Viljoen E, Smuts CM. Different dietary fatty acids are associated with blood lipids in healthy south African men and women: the PURE study. Int J Cardiol. 2014;172:368-74. https://doi.org/ 10.1016/j.ijcard.2014.01.023.

43. Wolmarans P, Danster N, Dalton A, Rossouw K, Schönfeldt H. Condensed food composition tables for South Africa. Medical Research Council: Cape Town; 2010.

44. Langenhoven M, Conradie P, Wolmarans P, Faber M. MRC food quantities manual. Parow: South African Medical Research Council; 1991.

45. Stewart A, Marfell-Jones M, Olds T, De Ridder H. International standards for anthropometric assessment. International Society for the Advancement of Kinanthropmetry: Lower Hutt, New Zealand; 2011.

46. Weber MA, Schiffrin EL, White WB, Mann S, Lindholm LH, Kenerson JG, et al. Clinical practice guidelines for the management of hypertension in the community. J Clin Hypertens. 2014;16:14-26. https://doi.org/10.1111/jch.12237.

47. WHO. Expert Committee on Diabetes Mellitus. Geneva: Diabetes Mellitus; 1985

48. Asher MI, Keil U, Anderson HR, Beasley R, Crane J, Martinez F, et al. International study of asthma and allergies in childhood (ISAAC): rationale and methods. Eur Respir J. 1995;8:483-91. http://www.ncbi.nlm.nih.gov/ pubmed/7789502. Accessed 8 Nov 2017

49. Morris A. Allsa Position Statement : Allergen Skin-Prick Testing. Allergy. 2006;19:22-5.

50. Levin ME, Muloiwa R, Motala C. Associations between asthma and bronchial hyperresponsiveness with allergy and atopy phenotypes in urban black south African teenagers : original article. South African Med J. 2011;101:472-6. https://journals.co.za/content/m_samj/101/7/EJC67627. Accessed 8 Nov 2017

51. Cox JL, Holden JM, Sagovsky R. Detection of postnatal depression. Development of the 10-item Edinburgh postnatal depression scale. $\mathrm{Br} J$ Psychiatry. 1987;150:782-6. https://doi.org/10.1192/BJP.150.6.782.

52. Tsai AC, Scott JA, Hung KJ, Zhu JQ, Matthews LT, Psaros C, et al. Reliability and validity of instruments for assessing perinatal depression in African settings: systematic review and meta-analysis. PLoS One. 2013;8:e82521. https://doi.org/10.1371/journal.pone.0082521.

53. Fairbrother N, Hutton EK, Stoll K, Hall W, Kluka S. Psychometric evaluation of the multidimensional assessment of fatigue scale for use with pregnant and postpartum women. Psychol Assess. 2008;20:150-8. https://doi.org/10.1037/ 1040-3590.20.2.150. 
54. Spong CY. Defining "term" pregnancy. JAMA. 2013;

55. Butt K, Lim K, Bly S, Cargill Y, Davies G, Denis N, et al. Determination of gestational age by ultrasound. J Obstet Gynaecol Canada. 2014;36:171-81.

56. Finster M, Wood M. The Apgar score has survived the test of time. Anesthesiology. 2005;49:314. https://doi.org/10.1097/01.sa.0000183993.56916.5c.

57. Johnson TS, Engstrom JL, Gelhar DK, Johnson, Teresa S.; Engstrom, Janet L. Gelhar DK. Intra- and interexaminer reliability of anthropometric measurements of term infants. J Pediatr Gastroenterol $\{\&\}$ Nutr. 1997.

58. Faber M, Spinnler Benadé AJ. Breastfeeding, complementary feeding and nutritional status of 6-12-month-old infants in rural KwaZulu-Natal. South African J Clin Nutr. 2007;20:16-24. https://hdl.handle.net/10520/EJC64971

59. Gray $\mathrm{CL}$, Levin ME, du Toit G. Egg sensitization, allergy and component patterns in African children with atopic dermatitis. Pediatr Allergy Immunol. 2016:27:709-15.

60. Palmer DJ, Sullivan T, Gold MS, Prescott SL, Heddle R, Gibson RA, et al. Effect of n-3 long chain polyunsaturated fatty acid supplementation in pregnancy on infants' allergies in first year of life: randomised controlled trial. BMJ. 2012;344(2):e184. https://doi.org/10.1136/bmj.e184.

61. Albers R, Antoine J-M, Bourdet-Sicard R, Calder PC, Gleeson M, Lesourd B, et al. Markers to measure immunomodulation in human nutrition intervention studies. Br J Nutr. 2005:94(3):452.

62. Pell LG, Bassani DG, Nyaga L, Njagi I, Wanjiku C, Thiruchselvam T, et al. Effect of provision of an integrated neonatal survival kit and early cognitive stimulation package by community health workers on developmental outcomes of infants in Kwale County, Kenya: study protocol for a cluster randomized trial. BMC Pregnancy Childbirth. 2016;16:265. https://doi.org/10. 1186/s12884-016-1042-5.

63. Abubakar A, Holding P, van Baar A, Newton CRJC, van de Vijver FJR. Monitoring psychomotor development in a resourcelimited setting: an evaluation of the Kilifi developmental inventory. Ann Trop Paediatr. 2008;28:217-26. https://doi.org/10.1179/146532808X335679.

64. Osei J, Baumgartner J, Rothman M, Matsungo TM, Covic N, Faber M, et al. lodine status and associations with feeding practices and psychomotor milestone development in six-month-old south African infants. Matern Child Nutr. 2017;13:e12408. https://doi.org/10.1111/mcn.12408.

65. Abubakar A, Holding P, Van de Vijver F, Bomu G, Van Baar A. Developmental monitoring using caregiver reports in a resource-limited setting: the case of Kilifi. Kenya Acta Paediatr. 2010;99:291-7. https://doi.org/ 10.1111/j.1651-2227.2009.01561.x.

66. Prado EL, Abubakar AA, Abbeddou S, Jimenez EY, Somé JW, Ouédraogo J-B. Extending the developmental milestones checklist for use in a different context in sub-Saharan Africa. Acta Paediatr. 2014;103:447-54. https://doi. org/10.1111/apa.12540.

67. Hungerford GM, Garcia D, Bagner DM. Psychometric evaluation of the brief infant-toddler social and emotional assessment (BITSEA) in a predominately hispanic, low-income sample. J Psychopathol Behav Assess. 2015;37:493-503. https:/doi.org/10.1007/s10862-015-9478-X.

68. Dold S, Baumgartner J, Zeder C, Krzystek A, Osei J, Haldimann M, et al. Optimization of a new mass spectrometry method for measurement of breast milk iodine concentrations and an assessment of the effect of analytic method and timing of within-feed sample collection on breast milk iodine concentrations. Thyroid. 2016;26:287-95. https://doi.org/10.1089/thy.2015.0317.

69. Brindle E, Lillis L, Barney R, Hess SY, Wessells KR, Ouédraogo CT, et al. Simultaneous assessment of iodine, iron, vitamin a, malarial antigenemia, and inflammation status biomarkers via a multiplex immunoassay method on a population of pregnant women from Niger. PLoS One. 2017;12:e0185868. https://doi.org/10.1371/journal.pone.0185868.

70. Osei J, Andersson M, van der Reijden O, Dold S, Smuts CM, Baumgartner J. Breast-milk iodine concentrations, iodine status, and thyroid function of breastfed infants aged 2-4 months and their mothers residing in a south African township. J Clin Res Pediatr Endocrinol. 2016;8:381-91. https://doi. org/10.4274/jcrpe.2720.

71. van Stuijvenberg ME, Schoeman SE, Lombard CJ, Dhansay MA. Serum retinol in 1-6-year-old children from a low socio-economic south African community with a high intake of liver: implications for blanket vitamin a supplementation. Public Health Nutr. 2012;15:716-24. https://doi.org/10. 1017/S1368980011002126.

72. Singh RJ. Quantitation of 25-OH-Vitamin D (25OHD) using liquid tandem mass spectrometry (LC-MS-MS). In: Garg U, Hammett-Stabler C, editors. Methods in molecular biology. Humana Press. 2010:509-17. https://doi.org/ 10.1007/978-1-60761-459-3_50.
73. Baumgartner J, Smuts CM, Malan L, Kvalsvig J, Van Stuijvenberg ME, Hurrell RF, et al. Effects of iron and n-3 fatty acid supplementation, alone and in combination, on cognition in school children : a randomized, double-blind, placebo-controlled intervention in South Africa. Am J Clin Nutr. 2012;96:1327-38.

74. Galetti V, Mitchikpe CES, Kujinga P, Tossou F, Hounhouigan DJ, Zimmermann MB, et al. Rural Beninese children are at risk of zinc deficiency according to stunting prevalence and plasma zinc concentration but not dietary zinc intakes. J Nutr. 2016;146:114-23. https://doi.org/10.3945/jn.115. 216606

75. Malan L, Baumgartner J, Zandberg L, Calder PC, Smuts CM. Iron and a mixture of DHA and EPA supplementation, alone and in combination, affect bioactive lipid signalling and morbidity of iron deficient south African school children in a two-by-two randomised controlled trial. Prostaglandins Leukot Essent Fat Acids. 2016;105:15-25. https://doi.org/10.1016/J.PLEFA.2015.12.005.

76. Möller M, Du Preez $J$, Harvey BH. Development and validation of a single analytical method for the determination of tryptophan, and its kynurenine metabolites in rat plasma. J Chromatogr B. 2012;898:121-9. https://doi.org/ 10.1016/j.jchromb.2012.04.030.

77. Bathina S, Das UN. Brain-derived neurotrophic factor and its clinical implications. Arch Med Sci. 2015;11:1164-78. https://doi.org/10.5114/aoms. 2015.56342.

78. Hsieh FY, Bloch DA, Larsen MD. A simple method of sample size calculation for linear and logistic regression. Stat Med. 1998;17:1623-34. http://personal. health.usf.edu/ywu/logistic.pdf. Accessed 21 Dec 2017

79. Chavatte-Palmer P, Tarrade A, Rousseau-Ralliard D. Diet before and during pregnancy and offspring health: the importance of animal models and what can be learned from them. Int J Environ Res Public Health. 2016;13

80. Bhutta ZA, Das JK, Rizvi A, Gaffey MF, Walker N, Horton S, et al. Evidencebased interventions for improvement of maternal and child nutrition: what can be done and at what cost? Lancet. 2013;382:452-77. https://doi.org/10. 1016/S0140-6736(13)60996-4.

81. Gumede S, Black V, Naidoo N, Chersich MF. Attendance at antenatal clinics in inner-city Johannesburg, South Africa and its associations with birth outcomes: analysis of data from birth registers at three facilities. BMC Public Health. 2017;17:443. https://doi.org/10.1186/s12889-017-4347-z.

82. Hunter-Adams J, Rother HA. Pregnant in a foreign city: a qualitative analysis of diet and nutrition for cross-border migrant women in Cape Town. South Africa Appetite. 2016;103:403-10.

83. Hunter-Adams J, Rother H-A. A qualitative study of language barriers between south African health care providers and cross-border migrants. BMC Health Serv Res. 2017;17:97. https://doi.org/10.1186/s12913-017-2042-5.
Ready to submit your research? Choose BMC and benefit from:
- fast, convenient online submission
- thorough peer review by experienced researchers in your field
- rapid publication on acceptance
- support for research data, including large and complex data types
- gold Open Access which fosters wider collaboration and increased citations
- maximum visibility for your research: over $100 \mathrm{M}$ website views per year
At BMC, research is always in progress.
Learn more biomedcentral.com/submissions 